\title{
Synthesis and characterization of starch-poly(methyl acrylate) graft copolymers using horseradish peroxidase
}

\author{
Su Wang ${ }^{\mathrm{a}}$, Qiang Wang ${ }^{\mathrm{a}, \mathrm{b}}$, Xuerong Fan ${ }^{\mathrm{a}, \mathrm{b}, *}$, Jin $\mathrm{Xu}^{\mathrm{a}}$, Ying Zhang ${ }^{\mathrm{a}}$, Jiugang Yuan ${ }^{\mathrm{a}}$, \\ Heling Jin ${ }^{\mathrm{a}}$, Artur Cavaco-Paulo ${ }^{\mathrm{b}, \mathrm{c}}$ \\ ${ }^{a}$ Key Laboratory of Science and Technology of Eco-Textile, Ministry of Education, Jiangnan University, Wuxi 214122, China \\ b International Joint Research Laboratory for Textile and Fiber Bioprocesses, Jiangnan University, Wuxi 214122, China \\ c Center of Biological Engineering, University of Minho, Braga 4710-057, Portugal
}

\section{A R T I C L E I N F O}

\section{Article history:}

Received 27 May 2015

Received in revised form

29 September 2015

Accepted 30 September 2015

Available online 9 October 2015

\section{Keywords:}

Starch

Horseradish peroxidase

Methyl acrylate

Graft polymerization

\begin{abstract}
A B S T R A C T
Horseradish peroxidase (HRP)-mediated graft polymerization in the presence of hydrogen peroxide $\left(\mathrm{H}_{2} \mathrm{O}_{2}\right)$ and acetylacetone (Acac) has been successfully applied to the synthesis of starch-poly(methyl acrylate) (PMA). The graft copolymer was characterized by Fourier transform infrared (FT-IR), elemental analysis, nuclear magnetic resonance $\left({ }^{1} \mathrm{H}\right.$ NMR and $\left.{ }^{13} \mathrm{C} N M R\right)$, and differential scanning calorimetry (DSC). FT-IR, elemental analysis and NMR confirmed that methyl acrylate (MA) was grafted onto starch successfully. DSC results showed the graft reaction had changed the crystalline regions of the gelatinized starch. The effects of $\mathrm{pH}$, MA content, HRP dosage, incubation temperature and time on grafting percentage (GP) and grafting efficiency (GE) were also investigated. The GP and GE under optimal conditions reached $30.21 \%$ and $45.13 \%$, respectively.
\end{abstract}

(c) 2015 Elsevier Ltd. All rights reserved.

\section{Introduction}

Starch is a naturally occurring high molecular weight compound, which has a wide range of applications in food and chemical industry and as a raw material in other industrial processes because it is available abundantly and has various properties. However, starch has some inherent limitations in its properties which make it unsuitable for some specific applications, thereby restricting its widespread use. Therefore, modification of starch using either physical or chemical methods is necessary in order to improve the properties of starch-based materials (Brockway \& Moser, 1963; Kiatkamjornwong, Mongkolsawat, \& Sonsuk, 2002). In recent years, attention has been particularly focused on chemically modified starches due to their varied properties, reproducibility, biodegradability and low-cost (Liu \& Su, 2005). Starch can be chemically modified by reactions such as hydrolysis, etherification, grafting, dextrinization and other methods (Meshram, Patil, Mhaske, \& Thorat, 2009). These modifications help to overcome the above mentioned limitations and improve the thickening, binding, gelling, adhesive and film forming

\footnotetext{
* Corresponding author at: Key Laboratory of Science and Technology of EcoTextile, Ministry of Education, Jiangnan University, Wuxi 214122, China.

E-mail address: wxfxr@163.com (X.Fan).
}

properties of starch, thereby widening the scope of its applications in different fields such as agriculture, medical, textile (Gao, Yu, \& Wang, 1998). Recently, a large number of researches have reported grafting of some vinyl monomers onto starch using chemical initiators, like ceric ammonium nitrate (Athawale \& Rathi, 1997), potassium permanganate/citric acid (Mostafa, 1995), potassium bromate-thiourea, (El-Rafie, Zahran, El-Tahlawy, \& Hebeish, 1995) and ammonium persulfate (Zhang et al., 2014). It should be noted that although the chemical methods for the graft polymerization of starch have many advantages such as high catalytic efficiency and less triggering time, it still has some disadvantages such as complexity associated with the modification process, which makes it difficult to control the reaction. Moreover, some chemical initiators are responsible for environmental pollution and also degrade the starch during modification. Thus, it is essential to find an eco-friendly alternative for these traditional initiators. With rapid developments in biological science, it has been realized that some inorganic initiators can be replaced by natural enzymatic catalysts (Shogren, Willett, \& Atanu, 2009). It has been proved that enzymatic catalysis is a powerful method for graft polymerization reaction in material modification (Hollmann \& Arends, 2012; Nyanhongo, Kudanga, Prasetyo, \& Guebitz, 2011). Thus, the modification of starch via enzymatic catalysis constitutes a green method of improving properties of starch and widening its scope of applications. 
Table 1

Elements content of soluble starch and grafted starch.

\begin{tabular}{|c|c|c|c|}
\hline Samples (Theoretical value) & $\mathrm{C}(\%)$ & $\mathrm{H}(\%)$ & $\mathrm{O}(\%)$ \\
\hline Soluble starch & $40.300(44.444)$ & $6.649(6.173)$ & $53.051(49.383)$ \\
\hline Grafted starch $(\mathrm{GP}=7.50 \%)$ & $41.800(45.332)$ & $6.593(6.242)$ & $51.607(48.635)$ \\
\hline Grafted starch $(\mathrm{GP}=30.21 \%)$ & $43.280(47.082)$ & $6.720(6.359)$ & $50.000(46.559)$ \\
\hline
\end{tabular}

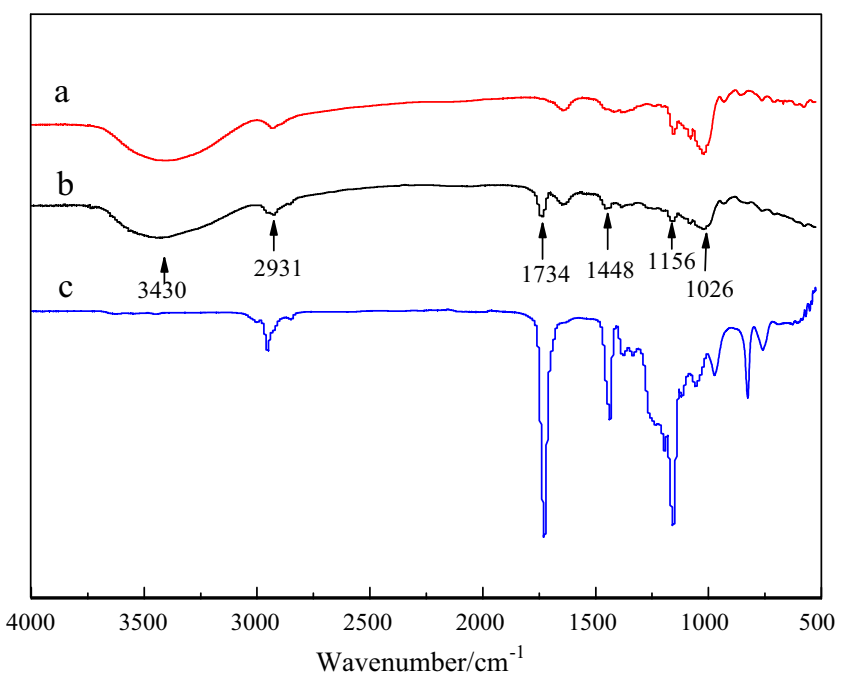

Fig. 1. FT-IR spectra of the soluble starch (a), graft copolymer (b) and PMA (c).

Horseradish peroxidase (HRP, EC1.11.1.7), an oxidoreductase obtained from the roots of horseradish, is a very popular and efficient biocatalyst, which has been used to catalyze free radical polymerizations of phenols (Ikeda, Sugihara, Uyama, \& Kobayashi, 1996) and anilines (Bruno et al., 1995; Teixeira, Lalot, Brigodiot, \& Maréchal, 1999). It has been reported that HRP can catalyze the oxidative coupling of many substrates like phenols and aromatic amines in the presence of hydrogen peroxide in aqueous, nonaqueous and interfacial media (Bhanu \& Gross, 2000). Derango et al. were the first to demonstrate the potential use of HRP and other oxidases as catalysts in the free radical polymerization of vinyl monomers (Derango, Chiang, Dowbenko, \& Lasch, 1992). Bhanu et al. studied HRP-catalyzed acrylamide polymerizations in an aqueous medium both in presence and in absence of surfactants. Also, polymerization in concentrated emulsions using sorbitan monooleate as the emulsifier was also reported (Bhanu \& Gross, 2002). Emery et al. reported that the free radical polymerization of acrylamide in water could be initiated by $\mathrm{HRP} / \mathrm{H}_{2} \mathrm{O}_{2} / 2$,4-pentanedione (Emery, Lalot, Brigodiot, \& Marechal, 1997). The graft polymerization of starch and acrylamide in an aqueous solution using an initiator system comprising of $\mathrm{HRP} / \mathrm{H}_{2} \mathrm{O}_{2} / 2$,4-pentanedione was reported by Shogren et al.(2009). The results showed that polyacrylamides were bonded to the starch skeleton to form branched chains with low molecular weights in the presence of $\mathrm{HRP} / \mathrm{H}_{2} \mathrm{O}_{2}$. In addition to this, Lv et al. showed that different monomers like dimethyl diallyl ammonium chloride (DMDAAC), p-hydroxybenzoic acid and resorcinol could be grafted onto starch in the system initiated by $\mathrm{HRP} / \mathrm{H}_{2} \mathrm{O}_{2}$ ( $\mathrm{Lv}$, Gong, \& Ma, 2012; Lv, Gong, Yan, \& Hou, 2012; Lv, Sun, Zhou, Liu, \& Ding, 2014).

It is well-known that the viscosity of native starch slurry is unstable and the film made from starch is brittle, which greatly limits its industrial applications. In the present work, HRP-mediated polymerization of starch and methyl acrylate (MA) has been studied, with an aim to graft flexible polymers onto starch chains. Besides this, this is an innovative method to substitute traditional chemical initiators by HRP in the starch modification process.

The polymerization of soluble starch with MA was characterized by FT-IR, elemental analysis, ${ }^{1} \mathrm{H}$ NMR, ${ }^{13} \mathrm{C}$ NMR, and DSC. The effects of the reaction conditions on graft copolymerization were also investigated.

\section{Materials and methods}

\subsection{Materials}

Soluble starch ( $\leq 13 \%$ water content) and hydrogen peroxide $(30 \%(w / v))$ were provided by Sinopharm Chemical Reagent Co (Shanghai, China). Horseradish peroxidase was obtained from Aladdin Reagent Ltd. (Shanghai, China). All the other chemicals used were commercially available and were of analytical purity.

\subsection{Horseradish peroxidase assay}

$2 \mathrm{~mL}$ HRP $(0.01 \mathrm{mg} / \mathrm{mL}), 2 \mathrm{~mL} \mathrm{H}_{2} \mathrm{O}_{2}$ (30\%(w/v)) and $25 \mathrm{~mL}$ gallic acid were added $(0.01 \mathrm{~g} / \mathrm{mL})$ to a $100 \mathrm{~mL}$ conical flask containing $20 \mathrm{~mL}$ phosphate buffer solution and then placed in an incubator shaker and allowed to react for $6 \mathrm{~h}$ at $30^{\circ} \mathrm{C}$. Then, $10 \mathrm{~mL}$ of anhydrous ether was poured into the reaction mixture to extract the product. The ether extract was used for analysis. The activity of HRP was measured using an UV/Vis spectrophotometer by monitoring the absorbance of the prepared solution at a wavelength of $420 \mathrm{~nm}$ and expressed in units defined as follows:

$\operatorname{HRP}(\mathrm{U} / \mathrm{mg})=E_{420} \times 8.5 \times E_{w}$

where $E_{420}$ is the absorbance at a wavelength of $420 \mathrm{~nm}, 8.5$ is the weight of the oxidized product that was extracted with $100 \mathrm{~mL}$ anhydrous ether. The absorbance at the wavelength of $420 \mathrm{~nm}$ is 1.000 , and $E_{\mathrm{W}}$ is the weight of the enzyme.

Then $\mathrm{pH}$ of phosphate buffer solution and the incubation temperature in the HRP activity assay were optimized. The $\mathrm{pH}$ value was optimized by measurement of activities at $\mathrm{pH}$ values ranging between 5 and 9 at $30^{\circ} \mathrm{C}$. For each of the temperatures studied (20, $30,40,50$ and $60^{\circ} \mathrm{C}$ ), the optimum $\mathrm{pH}$ of phosphate buffer solution, was chosen. The incubation procedure was the same as that described for $\mathrm{pH}$ optimization.

\subsection{Preparation of copolymers}

Soluble starch ( $2.5 \mathrm{~g}$, dry weight) and $90 \mathrm{~mL}$ water were placed in a three-necked, round-bottomed flask and gelatinized by stirring for $10 \mathrm{~min}$ at $100^{\circ} \mathrm{C}$ and then cooled to room temperature. Then $10 \mathrm{~mL}$ of $0.1 \mathrm{M}$ potassium phosphate buffer, $\mathrm{pH} 7.0$, 3.0 g MA, and specific amounts of Acac and HRP were successively added to the three-necked flask under a nitrogen atmosphere and stirring. Next, $2.0 \mathrm{~mL}$ of $\mathrm{H}_{2} \mathrm{O}_{2}(0.3 \%)$ was added dropwise within $1 \mathrm{~h}$. Finally, the reaction mixture was stirred for $5 \mathrm{~h}$ at $30^{\circ} \mathrm{C}$. After this, the reaction mixture was poured into $200 \mathrm{~mL}$ of absolute ethanol to precipitate the product (Lv et al., 2014; Shogren et al., 2009).

The product was poured into $200 \mathrm{~mL}$ of absolute ethanol, stirred for $24 \mathrm{~h}$ at room temperature, followed by centrifugation at $4000 \mathrm{rpm}$ for $10 \mathrm{~min}$ to remove the unreacted MA and other reagents and to get a mixture of the grafted copolymer and homopolymer. The mixture was weighed after it was dried to constant weight under vacuum at $50^{\circ} \mathrm{C}$ and extracted with acetone for $12 \mathrm{~h}$ to obtain the grafted starch. The homopolymer was gained from the acetone used in extraction by volatilization. And the 


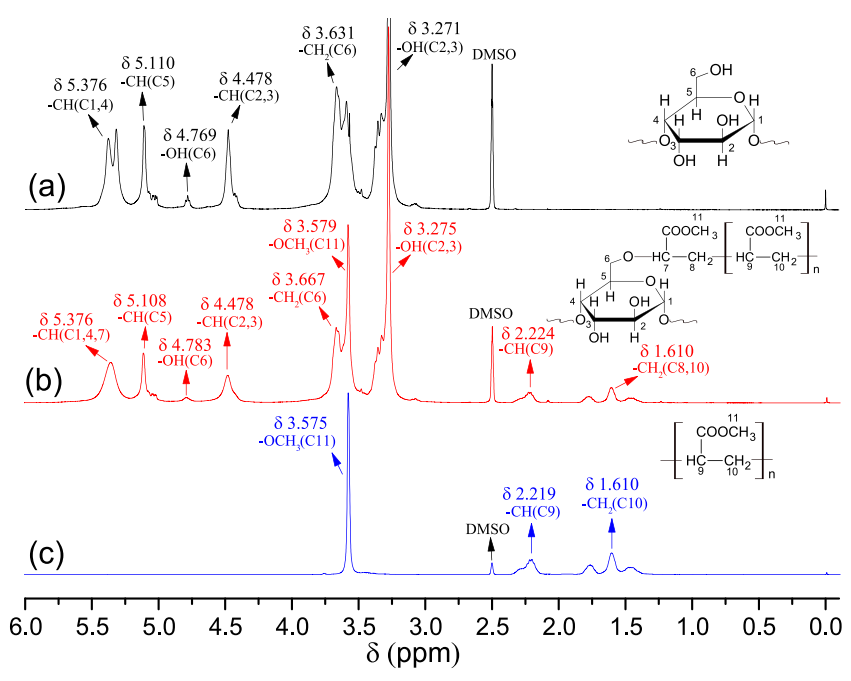

Fig. 2. ${ }^{1} \mathrm{H}$ NMR spectra of soluble starch (a), grafted starch (b) and PMA (c).

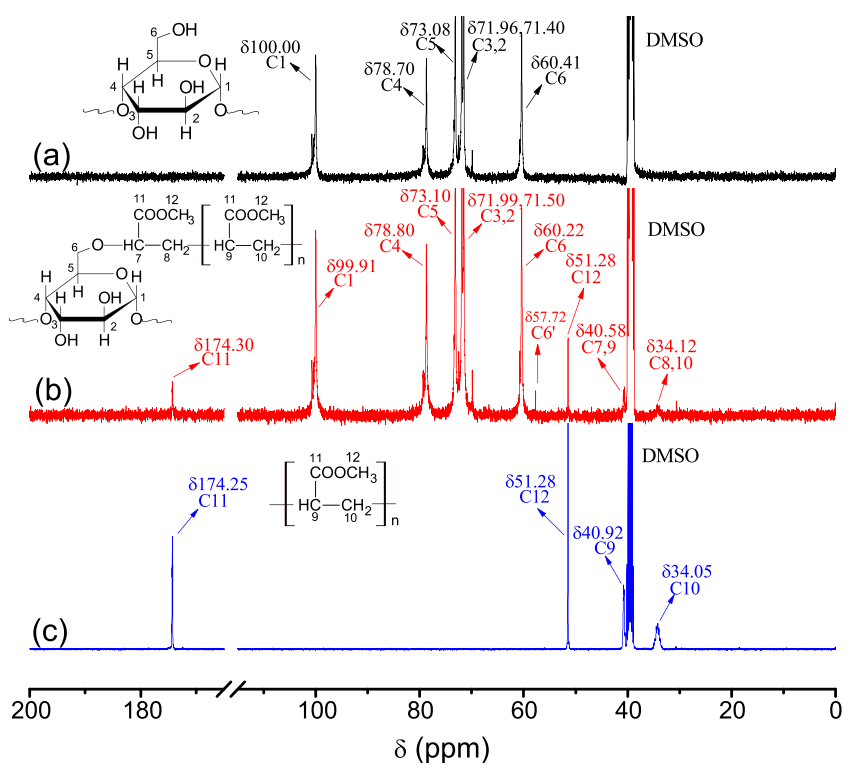

Fig. 3. ${ }^{13} \mathrm{C}$ NMR spectra of soluble starch (a), grafted starch (b) and PMA (c).

gelatinized starch was prepared under the same conditions as the preparation of the graft copolymers without $\mathrm{HRP} / \mathrm{Acac} / \mathrm{H}_{2} \mathrm{O}_{2}$.

The graft copolymer was hydrolyzed with $100 \mathrm{~mL}$ hydrochloric acid $(1.0 \mathrm{~mol} / \mathrm{L})$ in a water bath at $98^{\circ} \mathrm{C}$ for $10 \mathrm{~h}$ (The degree of hydrolysis of the copolymer was tested using a solution of $\mathrm{I}_{2}$ $\mathrm{KI})$. Then, the mixture was neutralized with a solution of sodium hydroxide $(1.0 \mathrm{~mol} / \mathrm{L})$ and washed until the washings were free of $\mathrm{Cl}^{-} \mathrm{s}$ (The washings were tested using a solution of $\mathrm{AgNO}_{3}$ ). The product obtained in the last step was dried to constant weight under vacuum at $50^{\circ} \mathrm{C}$, in order to obtain the polymer grafted onto soluble starch.

\subsection{Characterization}

\subsubsection{Grafting percentage and grafting efficiency}

The degree of grafting was reflected by the GP and GE. GP indicates the amount of PMA grafted onto the soluble starch. GE expresses the ratio of insoluble PMA grafted onto the soluble starch

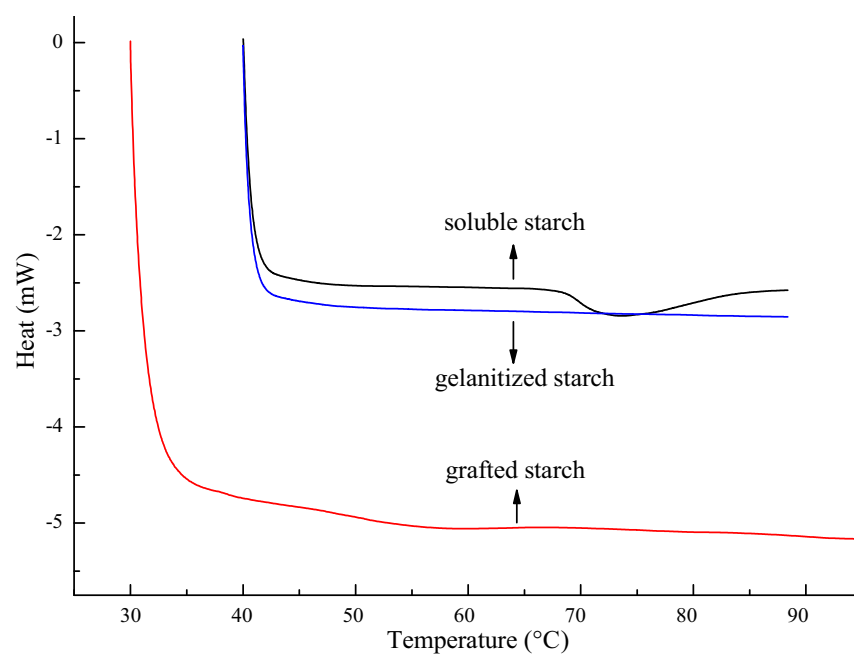

Fig. 4. DSC curves of the soluble starch, gelatinized starch and grafted starch.

to the total PMA. The GP and GE were calculated by using following equations:

GP $(\%)=\frac{M_{2}-M_{0}}{M_{2}} \times 100$
GE $(\%)=\frac{M_{2}-M_{0}}{M_{1}-M_{0}} \times 100$

where $M_{0}$ is the weight of the soluble starch taken; $M_{1}$ is the combined weight of the graft copolymer and the homocoplymer formed; $M_{2}$ is the weight of the graft copolymer (Guo et al., 2015).

\subsubsection{Optimization of the graft copolymerization}

The $\mathrm{pH}$ was optimized by testing at $\mathrm{pH}$ values of 5.0, 6.0, 7.0, 8.0, and 9.0 using MA 3\%, HRP $0.4 \%$ and $\mathrm{H}_{2} \mathrm{O}_{2} 0.6 \%$ in phosphate buffer at $40^{\circ} \mathrm{C}$ for $6 \mathrm{~h}$. The MA concentration was optimized using MA concentrations of $1,2,3,4$, and $5 \%$ at an optimum $\mathrm{pH}$ for the grafting reaction. The other grafting conditions were the same as those described for $\mathrm{pH}$ optimization. For optimization of enzyme concentration the enzyme concentrations tested were $0.1,0.2,0.3$, 0.4 and $0.5 \%$ at optimum conditions of $\mathrm{pH}$ and MA concentration. For optimizing the temperature, the temperatures tested were 20 , $30,40,50$ and $60^{\circ} \mathrm{C}$ using optimum an enzyme concentration. The incubation procedure was the same as described for the optimization of enzyme concentration. For optimization of the reaction time, the reaction times chosen were $3,4,5,6$ and $7 \mathrm{~h}$, the other reaction conditions being optimum, based on the above experiments.

\subsubsection{Fourier transform infrared spectroscopy (FT-IR)}

The FT-IR spectra were recorded on a Nicolet iS10 FT-IR spectrometer (Thermo Fisher Scientific, USA) using the ATR technique. The spectra were recorded in the absorption mode in the range of $4000-500 \mathrm{~cm}^{-1}$ with a $4 \mathrm{~cm}^{-1}$ resolution, using $\mathrm{KBr}$ pellets made from a mixture of polymer ( $1 \mathrm{wt} \%$ ) and $\mathrm{KBr}$.

\subsubsection{Elemental analysis}

$\mathrm{C}, \mathrm{H}$ and $\mathrm{O}$ elements of the graft copolymer and soluble starch samples were determined using a Vario ZL III elemental analyzer (Elementar, Germany).

\subsubsection{NMR analysis}

The ${ }^{1} \mathrm{H}$ NMR and ${ }^{13} \mathrm{C}$ NMR spectra of $20-50 \mathrm{mg}$ purified samples dissolved in 450-500 $\mu$ L of deuterated DMSO were recorded by using tetramethylsilane (TMS) as an internal standard on a Bruker Avance III spectrometer (Bruker, Germany) at an operating frequency of $400 \mathrm{MHz}$. 

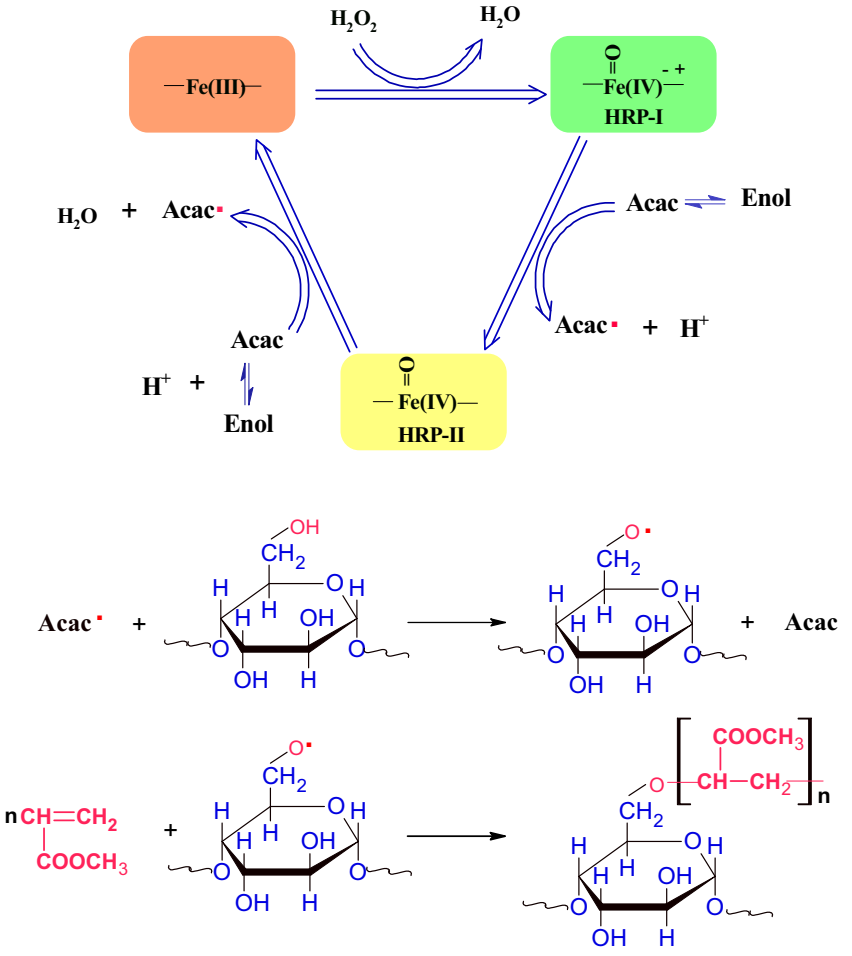

Fig. 5. Catalytic synthesis process of the enzymatic reaction.

\subsubsection{Differential scanning calorimetry (DSC)}

DSC experiments were performed using a differential scanning calorimeter TA-Q200 (Waters, Shanghai) with an $\mathrm{N}_{2}$ flow rate of $20 \mathrm{~mL} / \mathrm{min}$. The temperature was varied from 40 to $90^{\circ} \mathrm{C}$ at a heating rate of $10^{\circ} \mathrm{C} / \mathrm{min}$.

\section{Results and discussion}

\subsection{FT-IR analysis}

To demonstrate grafting reaction, the comparison of FT-IR spectra of soluble starch, graft copolymer, and PMA are shown in Fig. 1. The FT-IR spectrum of soluble starch (Fig. 1a) showed the characteristic absorption peaks at $3430 \mathrm{~cm}^{-1}, 2931 \mathrm{~cm}^{-1}$ and a triplet peak at $1156 \mathrm{~cm}^{-1}$ which are ascribed to the $\mathrm{O}-\mathrm{H}$ stretching, $\mathrm{C}-\mathrm{H}$ stretching and $\mathrm{C}-\mathrm{O}-\mathrm{C}$ stretching vibrations of the starch molecule, respectively (Zhang et al., 2014). The absorption peak at $1026 \mathrm{~cm}^{-1}$ is a characteristic of the glucose ring in the structure of starch. As shown in Fig. 1b, the characteristic peaks appearing at $3430 \mathrm{~cm}^{-1}$, $2931 \mathrm{~cm}^{-1}$ and $1026 \mathrm{~cm}^{-1}$ can be ascribed to the $\mathrm{O}-\mathrm{H}$ stretching vibration, $\mathrm{C}-\mathrm{H}$ stretching vibration and to the glucose ring of the starch, respectively, which is consistent with the spectrum of soluble starch (Fig. 1a). The peaks appearing at $1734 \mathrm{~cm}^{-1}$ and $1448 \mathrm{~cm}^{-1}$ (Fig. 1b) are due to $-\mathrm{COO}^{-}$stretching vibration in PMA. In contrast to these peaks, characteristic of the carbonyl functional group at $1734 \mathrm{~cm}^{-1}$ and $1448 \mathrm{~cm}^{-1}$, are observed in the FTIR spectrum of PMA (Fig. 1c). These results suggest formation of PMAgrafted starch using MA and starch.

\subsection{Elemental analysis}

The elemental analysis of soluble starch and grafted starch are presented in Table 1 . It can be seen that the $C$ and $O$ contents of grafted starch show obvious trends with changes in GP. The $C$ and $O$ contents of MA are $55.81 \%$ and $37.21 \%$, respectively. The contents of $\mathrm{C}$ and $\mathrm{O}$ in soluble starch are $40.30 \%$ and $53.05 \%$, respectively. It can be seen in Table 1 , that the $C$ and $O$ contents of grafted starch lie between those of soluble starch and MA. With the increase of GP, the measured values of the $C$ content increase and the measured values of the $\mathrm{O}$ content decrease, consisting with the change trends of the theoretical values. However, all the measured values of the $\mathrm{H}$, $O$ content are higher than the theoretical values. The errors between the measured values and the theoretical values were caused by water in the samples. These results further indicate that PMA chains have been successfully grafted onto the starch chains, and the graft reaction had obviously changed the element compositions of the starch.

\section{3. ${ }^{1} \mathrm{H}$ NMR analysis}

${ }^{1} \mathrm{H}$ NMR spectra of soluble starch, grafted starch and PMA are shown in Fig. 2. The ${ }^{1} \mathrm{H}$ NMR spectrum of soluble starch is showed in Fig. 2a, which is consistent with previous study (Vargha \& Truter, 2005). In addition to retaining the characteristic peaks of soluble starch, the new peak appears at 1.160 ppm in Fig. $2 \mathrm{~b}$, which is caused by the proton $\left(-\mathrm{CH}_{2}\right)$ of the grafted side chains. And the peak appearing at $2.224 \mathrm{ppm}$ is attributed to the proton $(-\mathrm{CH})$ of the grafted side chains, which is consistent with previous studies (Morgan, Michael, Daniel, Christian, \& Robert, 2011; Mou, Li, Wang, Fei, \& Liu, 2012). Furthermore, the obvious difference between the soluble starch and grafted starch appears at $5.376 \mathrm{ppm}$, which is caused by the proton $(-\mathrm{CH})$ in the first unit of the grafted side chains. This difference illustrates that the graft reaction increases the chemical shift of the proton $(-\mathrm{CH})$ in the first unit of the grafted side chains because the $O$ could decrease the shielding effect of the proton $(-\mathrm{CH})$ in the first unit. Thus, the difference is the forceful proof that PMA has been linked to the starch successfully. All the split peaks of the ${ }^{1} \mathrm{H}$ NMR spectrum of PMA (Fig. 2c) appear in the ${ }^{1} \mathrm{H}$ NMR spectrum of the grafted starch. Based on the ${ }^{1} \mathrm{H}$ NMR results, the grafting reaction between MA and starch can be confirmed. This result is also consistent with the results of FT-IR and element analysis as described above.

\section{4. ${ }^{13}$ C NMR analysis}

${ }^{1} \mathrm{H}$ NMR analysis provides a powerful indication that the graft reaction had taken place successfully. In order to further confirm that PMA had been grafted onto the molecular chains of the starch, ${ }^{13} \mathrm{C}$ NMR spectra of soluble starch, grafted starch and PMA were tested. As shown in Fig. 3a, the ${ }^{13} \mathrm{C}$ NMR spectrum of soluble starch presents the low field peaks at $\delta=100.00 \mathrm{ppm}$ due to anomeric carbons (C1), the peaks at $\delta=78.70 \mathrm{ppm}$ due to C4 (Zhang et al., 2014). In addition, the peaks in the range of $71-73 \mathrm{ppm}$ are attributed to carbon atoms $(\mathrm{C} 2,3,5)$ connected with $-\mathrm{OH}$ groups. The peaks at $\delta=60.41 \mathrm{ppm}$ belong to the carbon atoms (C6) of the $\mathrm{CH}_{2} \mathrm{OH}$ in glucose (Lan, Yu, Chen, Zou, \& Simon, 2010; Zou et al., 2012).

The ${ }^{13} \mathrm{C}$ NMR spectrum of grafted starch is shown in Fig. $3 \mathrm{~b}$. The peaks of carbon atom $\mathrm{C} 1-\mathrm{C} 5$ can be clearly identified for grafted starch, which is consistent with the chemical shifts of soluble starch. However, some new peaks can be observed after grafting. The peaks at $\delta=174.30 \mathrm{ppm}$ represent the carbon atoms (C11) of ester groups in the grafted side chains (Lv, Gong, \& Ma, 2012; Lv, Gong, Yan, et al., 2012; Mou et al., 2012; Vargha \& Truter, 2005). The peaks appear at $\delta=40.58 \mathrm{ppm}$ and $34.12 \mathrm{ppm}$ are responsible for carbon atoms $\left(-\mathrm{CH}-\mathrm{CH}_{2}-\right)$ n units in the grafted chains (Pal, Nasim, Patra, Ghosh, \& Panda, 2010; Sen, Kumar, Ghosh, \& Pal, 2009). The peaks at $\delta=51.28$ are attributed to $\mathrm{C} 12$ in the grafted chains. It should be noted that a new peak is observed at $\delta=57.72 \mathrm{ppm}$, which is close to the peak for C6 at $\delta=60.22 \mathrm{ppm}$. This new peak at $\delta=57.72 \mathrm{ppm}$ was caused by the shielding effect of a part of C6 linked to the grafted chain, which is a powerful evidence to support 

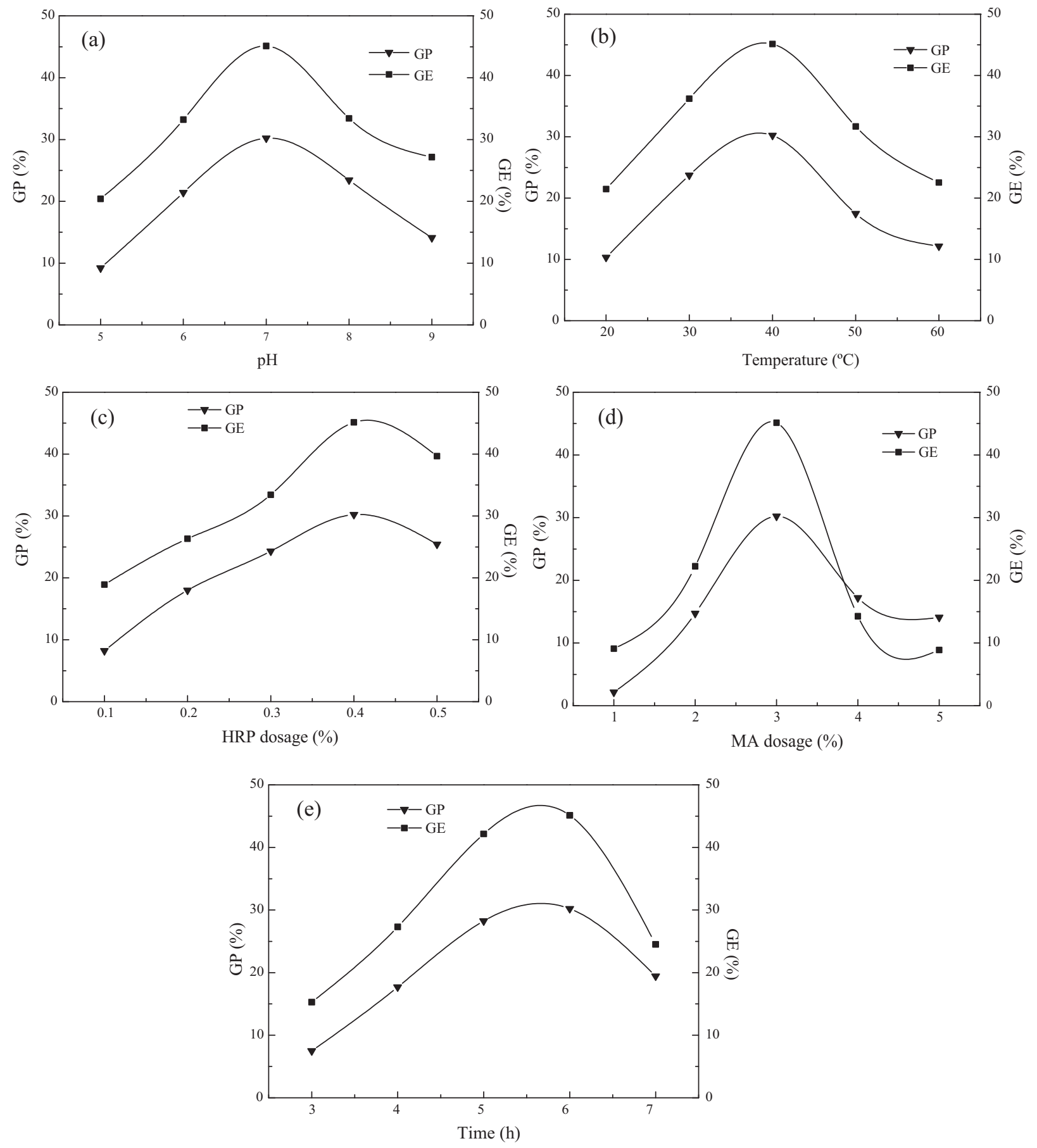

Fig. 6. Optimization of the process parameters: $\mathrm{pH}(\mathrm{a})$, incubation temperature (b), HRP dosage (c), MA dosage (d), and incubation time (e).

that PMA had been grafted onto the hydroxyl groups linked to C6 (Zhang, Xu, \& Wang, 2008), corresponding to the results of ${ }^{1} \mathrm{H}$ NMR (Fig. 2). The chemical shift of the proton $(-\mathrm{CH})$ in the first unit of the grafted side chains is different from the protons $(-\mathrm{CH})$ in other units of the grafted chains, which forms a new peak at $5.376 \mathrm{ppm}$. According to the chemical shifts of the carbon atoms (C6', C7) in Fig. 3b and the proton linked to C7 in Fig. 2b, it can be concluded that the covalent coupling of the oxygen free radicals linked to C6 and the free radicals of $\mathrm{C7}$ occurred, forming the key structure of $-\mathrm{CH}_{2}-\mathrm{O}-\mathrm{CH}-$ in the grafted copolymers. The forming of this key structure illustrates that the PMA was connected with the glucose units of starch. In addition, the peaks shown in the ${ }^{13} \mathrm{C}$ NMR spectrum of PMA (Fig. 3c) can be observed in Fig. 3b. Therefore, the results of ${ }^{13} \mathrm{C}$ NMR indicate that the graft reaction had taken place successfully.

\subsection{DSC analysis}

The DSC curves of soluble starch, gelatinized starch and graft copolymer are presented in Fig. 4. The DSC curve of soluble starch shows an endothermic peak at $73{ }^{\circ} \mathrm{C}$ due to the existence of crystalline regions. With the increase of the temperature, the hydrogen bonds between molecular chains were damaged, which caused the decrease in crystalline regions in the interior of the starch granules. Compared to soluble starch, the DSC curve of the gelatinized starch appears smooth, without any endothermic peaks, which is 
due to the disappearance of crystalline regions during the process of gelatinization. However, a weak endothermic peak appears at $55^{\circ} \mathrm{C}$ in the DSC curve of the grafted copolymer, probably due to the realignment of the grafted PMA chains with the formation of a new crystalline region, which was caused by the formation of hydrogen bonds between the alkyl esters of the grafted PMA chains. Thus, the DSC illustrates that the graft copolymers were successfully prepared and the grafted chains had changed the crystalline regions of the gelatinized starch.

\subsection{Catalytic mechanism and synthetic processes}

Based on previous studies (Durand, Lalot, Brigodiot, \& Marechal, 2000; Lalot, Brigodiot, \& Marechal, 1999) and above conclusions, the catalytic mechanism and possible synthetic processes involved in this study are presented in Fig. 5.

\subsection{Optimization of conditions for graft copolymerization}

The optimization of conditions for enzymatic grafting, including $\mathrm{pH}$ of the phosphate buffer, incubation temperature, concentrations of MA and HRP, and the incubation time were optimized as shown in Fig. 6. Referring to the graph (Fig. 6a), it is evident that HRP activity and GP reached a maximum at a $\mathrm{pH}$ value of 7.0 . With a temperature of $40^{\circ} \mathrm{C}$, maximum values of GP and GE were obtained, which can be seen from the curves for temperature (Fig. 6b). This can be attributed to the inactivation of enzymes at higher temperatures. Therefore, the optimum temperature for the copolymer formation was found to be $40^{\circ} \mathrm{C}$. Both the optimal results of $\mathrm{pH}$ and temperature were consistent with the results of $\mathrm{pH}$ and temperature on the activity of HRP enzyme (data not shown). From the curves of effects of HRP concentration (Fig. 6c) and MA concentration (Fig. 6d), the results showed that the GP increased greatly with the addition of MA until it reached its maximum value, with MA concentration of $3 \%$ and then decreased. This showed that increase in the concentrations of the monomer and HRP accelerate the homopolymerization reaction, rather than graft copolymerization after a certain limit, consequently decreasing the GP and GE. Finally, from the graph of incubation times (Fig. 6e), the optimum time was found to be $5.7 \mathrm{~h}$. Prolonging the reaction further resulted in decrease in GP and GE, which is a result of depolymerization of parts of the copolymer. In conclusion, the optimum conditions of grafting copolymerization of MA onto starch are: $3 \% \mathrm{MA}, 0.4 \% \mathrm{HRP}$, temperature $40^{\circ} \mathrm{C}, \mathrm{pH} 7.0$, and time $5.7 \mathrm{~h}$.

\section{Conclusions}

Modified starch is mainly prepared by graft copolymerization of monomers at reactive sites on the molecular backbone of starch for improvising the existing properties or for obtaining specific properties. In this study, a graft copolymer of starch with MA was synthesized using $\mathrm{HRP} / \mathrm{Acac} / \mathrm{H}_{2} \mathrm{O}_{2}$ system. The results of FT-IR, elemental analysis, ${ }^{1} \mathrm{H}$ NMR, ${ }^{13} \mathrm{C}$ NMR and DSC indicated that the target graft copolymers were formed by the catalysis of HRP. The present work showed that the graft copolymers of starch with MA were synthesized successfully by copolymerizing $2.5 \%$ of soluble starch with $3.0 \%$ of MA, using $\operatorname{HRP}(0.4 \%) / \mathrm{H}_{2} \mathrm{O}_{2}(0.6 \%) / \operatorname{Acac}(0.2 \%)$ at $40{ }^{\circ} \mathrm{C}$ and $\mathrm{pH}$ of 7.0 for $5.7 \mathrm{~h}$. This environmentally friendly process provides an attractive alternative for modification of starch, thereby extending its applications in the industry.

\section{Acknowledgments}

This work was financially supported by the Program for New Century Excellent Talents in University (NCET-12-0883), the Fundamental Research Funds for the Central Universities (JUSRP51312B), the Natural Science Foundation of Jiangsu Province (BK20140150), the Creative Fund of the Cooperation of Industry, Education and Academy of Jiangsu Province, China (BY2013015-18, BY2014023-05) and the Open Project Program of Key Laboratory of Eco-textiles, Ministry of Education, Jiangnan University (KLET1309).

\section{References}

Athawale, V. D., \& Rathi, S. C. (1997). Effect of the chain length of the alkyl group of alkyl methacrylates on graft polymerization onto starch using ceric ammonium nitrate as initiator. European Polymer Journal, 33(7), 1067-1071.

Bhanu, K., \& Gross, R. A. (2000). Horseradish peroxidase mediated free radical polymerization of methyl methacrylate. Biomacromolecules, 1, 501-505

Bhanu, K., \& Gross, R. A. (2002). HRP-mediated polymerizations of acrylamide and sodium acrylate. Green Chemistry, 4, 174-178.

Brockway, C. E., \& Moser, K. B. (1963). Grafting of poly(methyl methacrylate) to granular corn starch. Journal of Polymer Science: Part A, 1, 1025-1039.

Bruno, F. F., Akkara, J. A., Kaplan, D. L., Sekher, P., Marx, K. A., \& Tripathy, S. K. (1995). Enzyme-mediated two-dimensional polymerization of aromatic derivatives on a Langmuir trough. Industrial E' Engineering Chemistry Research, 34(11), 4009-4015.

Derango, A. R., Chiang, L. C., Dowbenko, R., \& Lasch, J. G. (1992). Enzyme-mediated polymerization of acrylic monomers. Biotechnology Techniques, 6, 523-526.

Durand, A., Lalot, T., Brigodiot, M., \& Marechal, E. (2000). Enzyme-mediated initiation of acrylamide polymerization: Reaction mechanism. Polymer, 41, 8183-8192.

El-Rafie, M. H., Zahran, M. K., El-Tahlawy, K. F., \& Hebeish, A. (1995). A comparative study of the polymerization of acrylic acid with native and hydrolyzed maize starches using a potassium bromate-thiourea dioxide redox initiation system. Polymer Degradation and Stability, 41, 73-85.

Emery, O., Lalot, T., Brigodiot, M., \& Marechal, E. (1997). Free-radical polymerization of acrylamide by horseradish peroxidase-mediated initiation. Journal of Polymer Science Part A: Polymer Chemistry, 35, 3331.

Gao, J. P., Yu, J. P., \& Wang, W. (1998). Graft copolymerization of starch-AN initiated by potassium permanganate. Journal of Applied Polymer Science, 68(12), 1965-1972.

Guo, Q. X., Wang, Y. Q., Fan, Y., Liu, X. W., Ren, S. Y., Wen, Y. Z., et al. (2015). Synthesis and characterization of multi-active site grafting starch copolymer initiated by $\mathrm{KMnO}_{4}$ and $\mathrm{HIO}_{4} / \mathrm{H}_{2} \mathrm{SO}_{4}$ systems. Carbohydrate Polymers, 117 , 247-254.

Hollmann, F., \& Arends, Isabel W. C. E. (2012). Enzyme initiated radical polymerizations. Polymers, 4, 759-793.

Ikeda, R., Sugihara, J., Uyama, H., \& Kobayashi, S. (1996). Enzymatic oxidative polymerization of 2,6-dimethylphenol. Macromolecules, 29, 8702-8705.

Kiatkamjornwong, S., Mongkolsawat, K., \& Sonsuk, M. (2002). Synthesis and property characterization of cassava starch grafted poly[acrylamide-co-(maleic acid)] superabsorbent via c-irradiation. Polymer, 43, 3915-3924.

Lalot, T., Brigodiot, M., \& Marechal, E. (1999). A kinetic approach to acrylamide radical polymerization by horseradish peroxidase-mediated initiation. Polymer International, 48, 288-292.

Lan, C., Yu, L., Chen, L., Zou, W., Simon, G., et al. (2010). Design, preparation and characterization of self-reinforced starch films through chemical modification. Macromolecular Materials and Engineering, 295, 1025-1030.

Liu, P., \& Su, Z. X. (2005). Surface-initiated atom transfer radical polymerization (SI-ATRP) of n-butyl acrylate from starch granules. Carbohydrate Polymers, 62 159-163.

Lv, S. H., Gong, R., \& Ma, Y. F. (2012). Structure and properties of the graft copolymer of starch and p-hydroxybenzoic acid using horseradish peroxidase. Polymers for Advance Technologies, 23, 1343-1349.

Lv, S. H., Gong, R., Yan, X. L., \& Hou, M. M. (2012). Structure and properties of graft copolymer of starch and resorcinol using HRP. Journal of Applied Polymer Science, 125, 541-547.

Lv, S. H., Sun, T., Zhou, Q. F., Liu, J. J., \& Ding, H. D. (2014). Synthesis of starch-g-p(DMDAAC) using HRP initiation and the correlation of its structure and sludge dewaterability. Carbohydrate Polymers, 103, 285-293.

Meshram, M. W., Patil, V. V., Mhaske, S. T., \& Thorat, B. N. (2009). Graft copolymers of starch and its application in textiles. Carbohydrate Polymers, 75, 71-78.

Mostafa, K. M. (1995). Graft polymerization of methyl acrylic acid on starch and hydrolyzed starches. Polymer Degradation and Stability, 50, 189-194.

Morgan, J. T. Michael, C. S., Daniel, T., Christian, S., \& Robert, G. G. (2011). New ${ }^{1} \mathrm{H}$ NMR procedure for the characterization of native and modified food-grade starches. Journal of Agricultural and Food Chemistry, 59, 6913-6919.

Mou, J., Li, X. R., Wang, H. H., Fei, G. Q., \& Liu, Q. (2012). Preparation, characterization, and water resistance of cationic acetylated starch-g-poly(styrene-butyl acrylate) surfactant-free emulsion. Starch/Stärke, $64,826-834$.

Nyanhongo, G. S., Kudanga, T., Prasetyo, E. N., \& Guebitz, G. M. (2011). Enzymatic polymer functionalisation: Advances in laccase and peroxidase derived lignocellulose functional polymers. Advances in Biochemical Engineering-Biotechnology, 125, 47-68. 
Pal, S., Nasim, T., Patra, A., Ghosh, S., \& Panda, A. (2010). Microwave assisted synthesis of polyacrylamide grafted dextrin (Dxt-g-PAM): Development and application of a novel polymeric flocculant. International Journal of Biological Macromolecules, 47, 623-631.

Sen, G., Kumar, R., Ghosh, S., \& Pal, S. (2009). A novel polymeric flocculant based on polyacrylamide grafted carboxymethyl starch. Carbohydrate Polymers, 77 , 822-831.

Shogren, R. L., Willett, J. L., \& Atanu, B. (2009). HRP-mediated synthesis of starch-polyacrylamide graft copolymers. Carbohydrate Polymers, 75, 189-191.

Teixeira, D., Lalot, T., Brigodiot, M., \& Maréchal, E. (1999). Beta-diketones as key compounds in free-radical polymerization by enzyme-mediated initiation. Macromolecules, 32, 70-72.
Vargha, V., \& Truter, P. (2005). Biodegradable polymers by reactive blending trans-esterification of thermoplastic starch with poly(vinyl acetate) and poly(vinyl acetate-co-butyl acrylate). European Polymer Journal, 41, 715-726.

Zhang, Z., Chen, P. R., Du, X. F., Xue, Z. H., Chen, S. S., \& Yang, B. J. (2014). Effects of amylose content on property and microstructure of starch-graft-sodium acrylate copolymers. Carbohydrate Polymers, 102, 453-459.

Zhang, O., Xu, K., \& Wang, P. (2008). Study structure and molecular dynamics of starch/poly(sodium acrylate)-grafted superabsorbent by ${ }^{13} \mathrm{C}$ solid state NMR. Fibers and Ploymers, 9, 271-275.

Zou, W., Yu, L., Liu, X. X., Chen, L., Zhang, X. Q., Qiao, D. L., et al. (2012). Effects of amylose/amylopectin ratio on starch-based superabsorbent polymers. Carbohydrate Polymers, 87, 1583-1588. 